\title{
Desain Komunikasi Visual Sign System Sebagai Sarana Penunjang Informasi Pada Universitas Raharja
}

\author{
Mukti Budiarto ${ }^{1}$, Dewi Immaniar Desrianti ${ }^{2}$, Regita Cahyani* $*^{3}$ \\ 1,2,3 Program Studi Teknik Informatika Sains Dan Teknologi Universitas Raharja. \\ E-mail: ${ }^{1}$ mukti@raharja.info, ${ }^{2}$ dewi.immaniar@ raharja.info, ${ }^{* 3}$ regita.cahyani@ raharja.info
}

\begin{abstract}
Abstrak
Seiring berkembangnya zaman, segala sesuatu menjadi lebih kompleks. Salah satu contohnya adalah tata letak atau penempatan ruang publik yang sering kali berubah-ubah seiring berjalannya waktu pada Universitas Raharja. Dengan perubahan yang kerap terjadi, informasi tentang tata letak di area Universitas Raharja menjadi terhambat. Permasalahan mengenai Sign system pada area Universitas Raharja kurang lengkap, dimana tidak adanya petunjuk arah yang menunjukan tata letak ruangan pada area ini, tujuan penelitian ini untuk menghasilkan sign system yang meningkatkan daya tarik audiens untuk melihat dan memenuhi kebutuhan informasi untuk Universitas Raharja, dengan dibuatnya desain sign system yang menarik, informatif, dan komunikatif yang didukung dengan pemilihan placement yang tepat diharapkan dapat membantu civitas Universitas Raharja dalam menunjukan arah maupun lokasi yang ingin dituju. Data yang diperoleh dalam penelitian ini merupakan hasil dari beberapa metode seperti observasi, wawancara, dan studi pustaka, serta penelitian ini dianalisis dengan SWOT dan Perancangan Media. Hasil dari penelitian ini adalah penerapan sign system di beberapa titik Universitas Raharja, seperti pada koridor Gedung Modern, koridor Gedung Lake View, Kantin, Masjid, Basement, serta Tempat Parkir. Sehingga memiliki kesimpulan yaitu untuk penyampaian informasi yang informatif dan komunikatif pada Universitas Raharja diperlukan media sign system dengan bahasa indonesia dan arah panah yang mudah dimengerti dan dipahami oleh civitas Universitas Raharja.
\end{abstract}

Kata Kunci - Media, Sign system, Informasi.

\begin{abstract}
As time goes by, things become more complex than before. One of them is either the layout or the placement of the public that often changes over time at Raharja University. With frequent changes, information about the layout in the Area of Raharja University became obstructed. The problem about the Sign system in the area of Raharja University is not complete, where there are no directions that show the layout of the room in this area, the purpose of this research is to produce a sign system that increases the attractiveness of the audience to see and meet the needs of information at Raharja University, with the design of an attractive, informative, and communicative sign system supported by the selection of appropriate placement is expected to help the civitas of Raharja University in showing the direction and location to be intended. The data obtained during this study used observation methods, interviews, and library studies, and this research was analyzed with SWOT and Media Design. The result of this research is the application of sign system in several points of Raharja University, such as in the corridor of Modern Building, a corridor of Lake View Building, Canteen, Mosque, Basement, and Parking Lot. So that it has a conclusion that is for the delivery of informative and communicative information at The University of Raharja required a media sign system with the Indonesian language and arrow direction that is easy to understand and understand by the civitas Raharja University.
\end{abstract}

Keywords - Media, Sign System, Information. 


\section{PENDAHULUAN}

Dengan seiring berkembangnya zaman, segala sesuatu menjadi lebih kompleks. Salah satu dari contohnya adalah penempatan atau tata letak ruang publik yang sering kali berubah seiring berjalannya waktu. Karena perubahan yang kerap terjadi, pengetahuan ataupun informasi tentang ruang publik menjadi terhambat. Sehingga, untuk menjembatani masalah tersebut agar tercipta efisiensi penyampaian informasi dibuatlah sign system.

Sign system atau sistem tanda secara umum dapat diartikan sebagai media interaksi manusia dengan ruang publik melalui bentuk visual. Penerapan sign system dapat membantu masyarakat untuk mengetahui letak suatu tempat atau jalan yang ingin dituju. "Sign system atau sistem tanda merupakan alat bantu yang digunakan manusia untuk berinteraksi dengan ruang, baik itu ruang publik, gedung perkantoran, sekolah, dan sebagainya" ${ }^{[1]}$, "Sistem rambu merupakan alat komunikatif bagi masyarakat dalam mengetahui area, ruangan maupun suatu

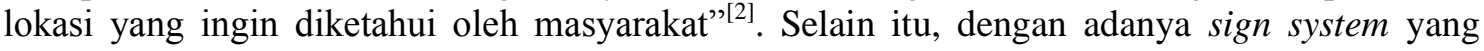
informatif dan menarik dapat menghemat waktu dan tenaga. Tanpa adanya sign system pada suatu area, dapat menghambat aktivitas pada area tersebut dan menjadi tidak efektif karena kurang tersampaikannya informasi yang dibutuhkan oleh civitas Universitas Raharja.

Tujuan penelitian ini untuk menghasilkan sign system yang meningkatkan daya tarik audience untuk melihat dan memenuhi kebutuhan informasi pada Universitas Raharja, juga untuk menghasilkan sign system yang informatif, komunikatif, dan mudah dipahami oleh audience pada area Universitas Raharja, dan dengan placement sign system yang tepat, diharapkan dapat membantu menunjukan arah lokasi yang ingin dituju

Manfaat Penelitian ini agar Universitas Raharja memiliki sign system yang menarik secara visual dan dapat membantu menunjukan arah, sign system ini dapat menjadi sarana komunikasi yang informatif dan mudah dipahami oleh masyarakat di area Universitas Raharja, sign system yang telah dirancang dapat menunjukan arah lokasi yang dituju pada area Universitas Raharja.

Sehingga memiliki kesimpulan bahwa penyampaian informasi yang informatif dan komunikatif pada Universitas Raharja dapat melalui media sign system dengan bahasa indonesia dan arah panah yang mudah dimengerti dan dipahami oleh civitas Universitas Raharja. Lalu dengan placement sign system yang telah ditentukan dengan jelas dan diletakan pada tempattempat yang strategis, sehingga dapat menunjukan arah lokasi yang ingin dituju.

\section{METODE PENELITIAN}

Dalam penelitian ini yang berjudul "Perancangan Desain Komunikasi Visual Sign System Sebagai Sarana Penunjang Informasi Pada Universitas Raharja" penulis menggunakan metode penelitian sebagai berikut: (1) Metode pengumpulan data melalui (a) Observasi, penelitian yang dilakukan secara langsung pada Kampus Universitas Raharja, (b) Wawancara, dengan melakukan wawancara langsung kepada pihak yang bersangkutan demi memperoleh informasi yang jelas langsung kepada narasumber atau stakeholder di Universitas Raharja. (c) Studi Pustaka, metode pengumpulan data dari sumber buku-buku, jurnal maupun media tertulis tentang jenis-jenis sign, kategori sign, karakteristik sign yang tepat untuk digunakan dalam perancangan sign system di area kampus. (2) Metode analisa perancangan media dengan menggunakan software penunjang desain yaitu Adobe Photoshop CS6 untuk mengubah informasi yang didapat menjadi ide atau gagasan yang memiliki nilai visual yang menarik. (3) konsep desain yang digunakan yaitu Perencanaan Media, Perencanaan Pesan, Perencanaan Visual, menjadikannya modern dan kreatif, yang nantinya dapat dipergunakan dan membantu civitas Universitas Raharja. 


\section{LITERATURE REVIEW}

Berikut adalah literature review yang terkait dengan topik penelitian :

Penelitian yang dilakukan oleh Andrijanto, MS. (2018 ${ }^{[3]}$ berjudul "Perancangan Alternatif Sign System Sebagai Informasi Lokasi Penjualan Di Pasar Legi Kota Gede". Tujuan penelitian ini membuat sign system yang akan memudahkan para pembeli untuk mencari tempat ataupun arah ke lapak pedagang yang dituju dan juga meningkatan rasa nyaman yang datang ke Pasar Legi Kotagede Yogyakarta.

Penelitian yang telah dilakukan oleh Ramadia, dkk (2017) ${ }^{[4]}$ yang berjudul "Perancangan Komunikasi Visual Sign System Semen Padang Hospital". Tujuan dalam penelitian ini adalah guna memberikan informasi yang komunikatif, menambah kesan estetik atau menarik, serta menciptakan public image terhadap pengunjung Semen Padang Hospital.

Penelitian yang dilakukan oleh Adzhar dan Wirania Swasty $(2019)^{[5]}$ berjudul "Perancangan Sign System Yang Terintegrasi Website Sebagai Media Informasi". Penelitian ini bertujuan untuk meningkatkan angka wisatawan Setu Babakan. Selain memperbaiki wayfinding dan sign system dengan membuat media informatif website untuk memberikan informasi.

Penelitian yang dilakukan oleh Putra, dkk $(2018)^{[6]}$ berjudul "Redesign Sign System Puskesmas Lubuk Buaya Koto Tangah Kota Padang". Penelitian ini dilaksanakan untuk memberikan informasi arah ruangan kepada pengunjung dan meningkatkan kenyamanan pengunjung.

Penelitian yang dilakukan oleh Mujabfaqni dan Tri Cahyo Kusumandyoko. (2016) ${ }^{[7]}$ berjudul "Perancangan Sign System Taman Flora Surabaya". Penelitian ini bertujuan untuk memudahkan para pengunjung dalam memahami informasi yang ada di Taman Flora.

Penelitian yang dilakukan oleh Sunarya, dkk (2016) ${ }^{[8]}$ dengan judul "Desain Media Sign System dan Himbauan Sebagai Penunjang Informasi Pada Yayasan Perguruan Islam Attaqwa". Tujuan Penelitian ini yaitu membuat media sign system dan himbauan yang nantinya menjadi salah satu media informasi yang efektif, dan diharapkan audiens mengerti pada peraturan yang telah ditetapkan oleh sekolah.

Penelitian yang dilakukan oleh Rizqullah, Mohamad Farid dan Wirania Swasty, $(2019)^{[9]}$ berjudul "Perancangan Media Informasi Kota Tua Jakarta Utara Melalui Sign System Yang Terintegrasi Website". Tujuan dari peneliti merancang sign system Kota Tua Jakarta yang efektif namun informatif dan terintegrasi dengan website resmi untuk membantu memecahkan permasalahan navigasi serta informasi dan kisah sejarah yang perlu diketahui pengunjung.

Penelitian yang dilakukan oleh Hendrizal, (2019) ${ }^{[10]}$ berjudul "Perancangan Sign System Pada Master Plan Kampus Universitas Negeri Padang". Tujuan perancangan sign system pada master plan Universitas Negeri Padang sebagai petunjuk arah yang informatif, komunikatif dan efektif.

Penelitian yang dilakukan oleh Tsao, dkk, (2020) ${ }^{[11]}$ berjudul "Universal Design Evaluation Applied On Station Sign System Innovation Design". Tujuan penelitian ini adalah membuat sign system untuk lorong-lorong utama di Stasiun Banqiao di New Taipei City, Taiwan.

Penelitian yang dilakukan oleh Iftikhar, H. Salman Asghar and Yan Luximon, $(2020)^{[12]}$ berjudul "The efficacy of campus wayfinding signage: a comparative study from Hong Kong and Pakistan". Penelitian ini bertujuan untuk menyelidiki perbedaan budaya dan individual yang mempengaruhi perilaku wayfinding.

\section{HASIL DAN PEMBAHASAN}

\subsection{Perencanaan Visual}

Perancangan sign system ini menampilkan visual dengan menggunakan ilustrasi, warna dan tipografi yang dapat mewakili serta menyampaikan informasi yang akan disampaikan. Visual sign system ini juga menggunakan warna bernuansa hijau sebagai branding Universitas

239 
Raharja yang disebut dengan green campus serta pemilihan tipografi yang menarik dan mudah dibaca oleh audience.

\section{Tujuan Visual}

Tujuan Visual dalam perancangan sign system ini adalah dengan dibuatnya sign system yang di rancangan dengan visual yang menarik serta terdapat ilustrasi, warna, dan tipografi yang menunnjang keindahan diharapkan dapat mempermudah dalam menyampaikan informasi kepada audience yang berada di area Universitas Raharja.

\section{Strategi Visual}

Strategi visual dalam perancangan sign system ini adalah membuat visual dengan desain yang modern. Contohnya dengan menggunakan warna desain bernuansa pastel, pemilihan font serif, dan dengan menambahkan ilustrasi yang mendukung seperti daun-daun maupun shapeshape guna menambah keindahan pada sign system yang dirancang.

\section{Penulisan Naskah (Copywriting)}

Pada perancangan desain komunikasi visual terdapat salah satu unsur penting yaitu teks ataupun tulisan yang mewakili penyampaian informasi, dimana teks dibuat ditujukan untuk dapat dimengerti dan tepat pada sasaran penerima informasi. Dalam perancangan sign system ini menggunakan beberapa unsur desain komunikasi visual seperti teks, ilustrasi, serta warna. Teks adalah salah satu unsur yang ada dalam desain komunikasi visual, dan berikut adalah beberapa penjelasan bagian dari teks yang digunakan dalam perancangan ini:

a. Naskah (Body Copy)

Dalam naskah ini mewakili penjelasan secara rinci mengenai informasi ataupun pesan yang ingin disampaikan melalui media sign system ini. Naskah dalam perancangan ini berisikan informasi tentang petunjuk arah, ruangan-ruangan, serta tata letak yang terdapat pada area Universitas Raharja.

b. Gambar/Ilustrasi

Gambar atau ilustrasi pada perancangan sign system ini dirancang dengan mengilustrasikan sebuah ruangan maupun menampilkan arah panah. Gambar atau ilustrasi yang digunakan bertujuan untuk memberikan gambaran kepada audience tentang arah, ruangan, maupun tata letak. Serta, dengan menampilkan ilustrasi yang telah disesuaikan dengan fungsi dan penyampaian informasinya akan membantu audience yang tidak dapat membaca.

c. Logo

Logo merupakan pencerminan sebuah lembaga ataupun simbol khusus yang dimiliki oleh suatu lembaga. Logo yang digunakan dalam perancangan sign system ini adalah logo Universitas Raharja, dimana logo ini sebagai branding yang dapat memudahkan audience dalam mengingat identitas Universitas Raharja.

\section{Pengarahan Visualisasi (Art Directing)}

Perancangan media komunikasi visual ini dirancang untuk menarik minat masyarakat dan memiliki ciri khas tersendiri, oleh karena itu dalam proses visualisasinya harus diperhatikan hal-hal yang mempengaruhi kegunaan nilai seni dari media komunikasi visual tersebut. Saat menentukan elemen warna yang dipilih, font yang digunakan, tata letak atau tata letak aplikasi, dan model tampilan grafis yang sesuai dengan model yang dipilih untuk ditampilkan di setiap desain media. Oleh karena itu, diperlukan gambaran visualisasi yang dipilih dan dapat digunakan dalam media desain yaitu :

a. Warna

Warna yang digunakan dalam perancangan sign system ini memilih warna hijau sebagai warna yang dominan, dikarenakan warna hijau adalah identitas dari Universitas Raharja. Pemilihan warna hijau olive ini didukung dengan trend warna yang lebih pastel atau warna yang tidak mencolok. Warna hijau yang dikombinasikan dengan warna putih diharapkan menjadi perpaduan yang sejuk, cantik, dan memberikan kesan mewah. 


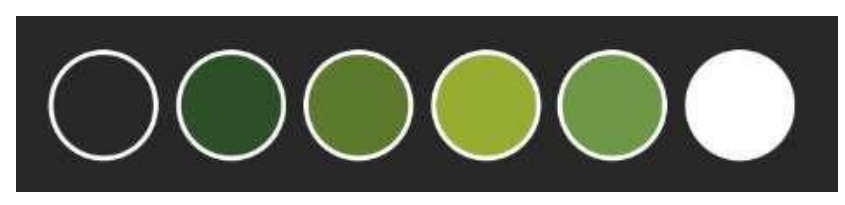

Gambar 1. Palette Warna

a) Hijau : Alami, kesehatan, pandangan yang sejuk, pembaruan.

b) Putih : Kemurnian/suci, bersih, kecermatan, innocent (tanpa dosa), steril, kematian.

c) Hitam : Kekuatan, seksualitas,kemewahan, kematian, misteri, ketakutan, ketidakbahagiaan, keanggunan.

b. Tipografi

Jenis huruf yang dipilih dalam perancangan sign system ini menggunakan jenis huruf serif, dimana dengan trend saat ini yang lebih minimalis serta didukung oleh warna yang dipilih diharapkan dapat menarik dan tersampaikannya informasi. Jenis huruf ini mudah dibaca serta cocok dengan gaya penampilan grafis desain yang dipilih, serta huruf yang digunakan juga free license yang bebas digunakan untuk siapapun. Berikut adalah rincian huruf yang digunakan:

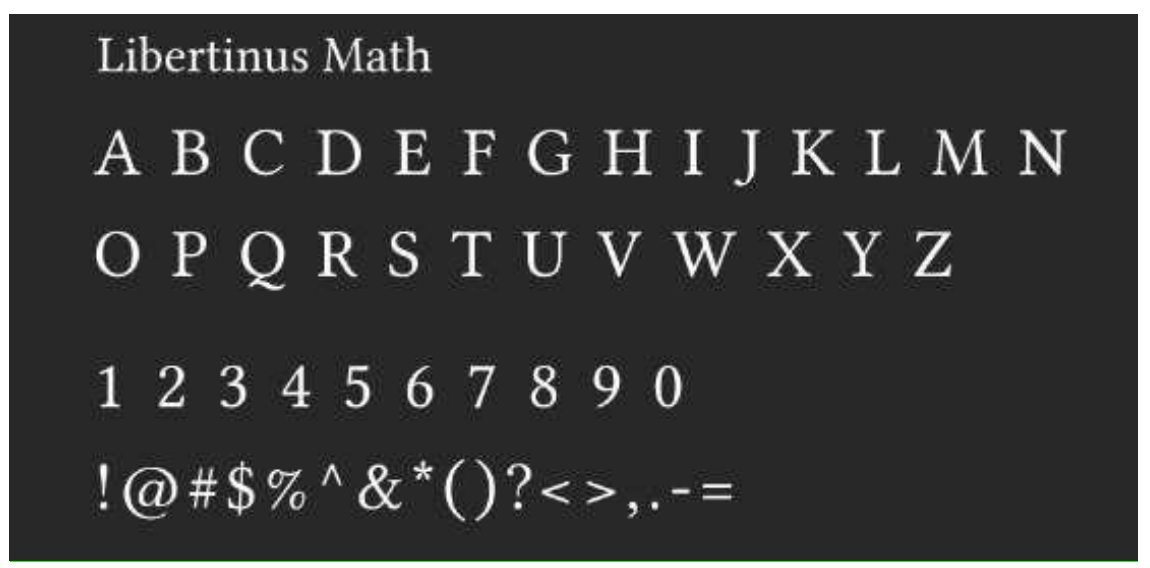

Gambar 2. Font Libertinus Math

c. Layout

Layout merupakan tata letak atau penempatan sesuatu hal yang disusun secara utuh dari segi warna, tipografi, gambar, maupun teks. Layout dalam perancangan sign system ini disusun dengan proporsi yang tepat, dimana judul, nama tempat, arah panah, serta logo tersusun dengan secara rapi dan konsisten.

d. Gaya penampilan grafis

Gaya penampilan grafis yang dipilih dalam perancangan sign system adalah minimalis trend yang dipadukan dengan warna pastel olive dan penggunaan jenis huruf serif. Gaya ini menonjolkan kesan sejuk, sederhana, namun mewah yang didukung dengan penambahan ornamen ilustrasi daun. 
e. Ilustrasi/Gambar

Ilustrasi atau gambar yang digunakan dalam perancangan sign system ini adalah beberapa icon yang menggambarkan ruangan tersebut dan daun. Dimana ilustrasi atau gambar ini dapat mendukung penyampaian pesan yang ingin disampaikan serta menambah estetika dalam desain ini. Berikut beberapa ilustrasi serta gambar yang digunakan:

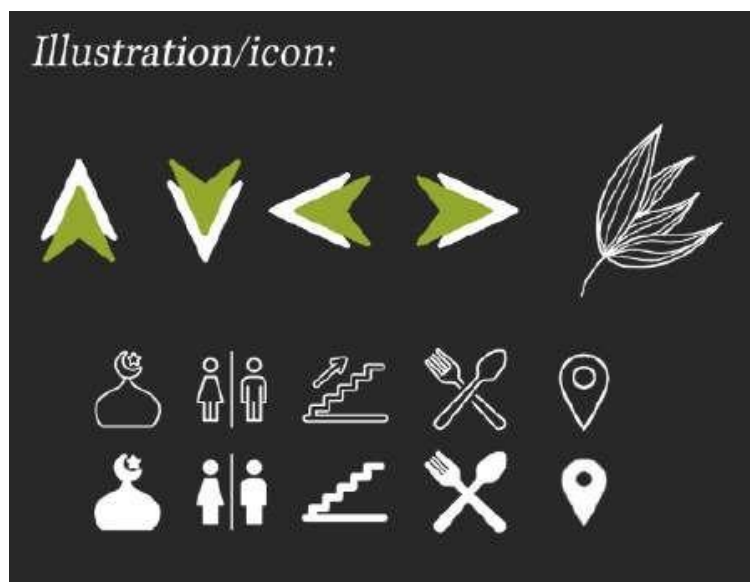

Gambar 3. Ilustrasi

\subsection{Proses Desain}

Pada perancangan sign system ini terdapat beberapa proses desain yang dilewati, berikut proses desain sign system:

\section{Layout Kasar}

Layout Kasar merupakan salah satu elemen desain, dimana layout kasar ini juga disebut dengan sketsa yang dibuat menggunakan pensil gambar, serta hasilnya akan diterapkan dalam perancangan sebuah desain atau digunakan sebagai acuan standarisasi desain yang dibuat. Berikut adalah layout kasar perancangan sign system:

- Koridor Kanan Lantai 1 Gedung Modern

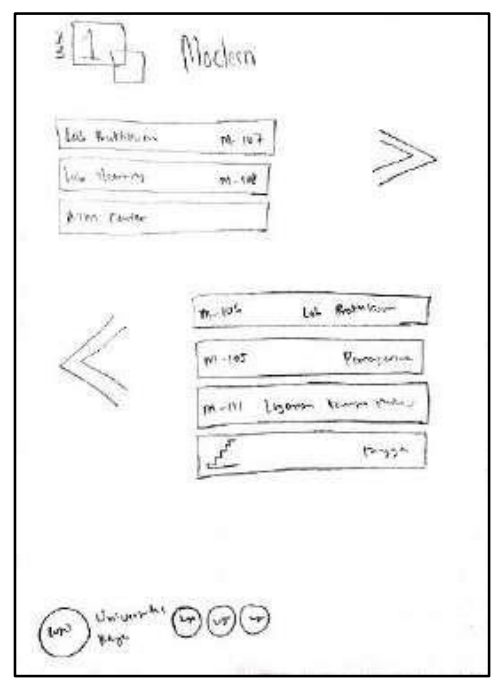

Gambar 4. Layout Kasar Koridor Kanan Lantai 1 Gedung Modern 
- Koridor Kiri Lantai 1 Gedung Modern

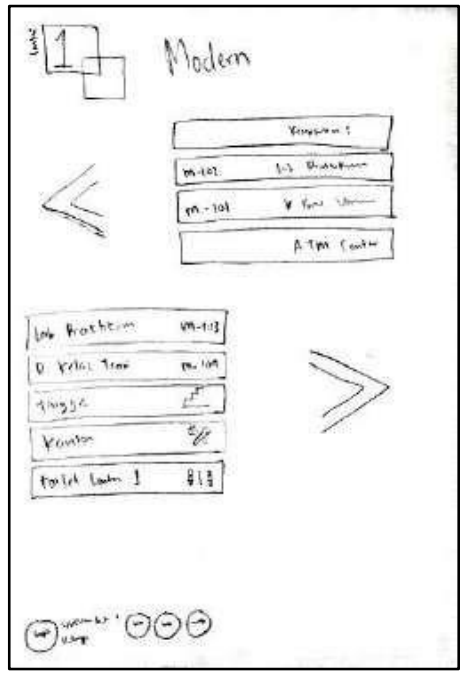

Gambar 5. Layout Kasar Koridor Kiri Lantai 1 Gedung Modern

- Koridor Kanan Lantai 2 Gedung Modern

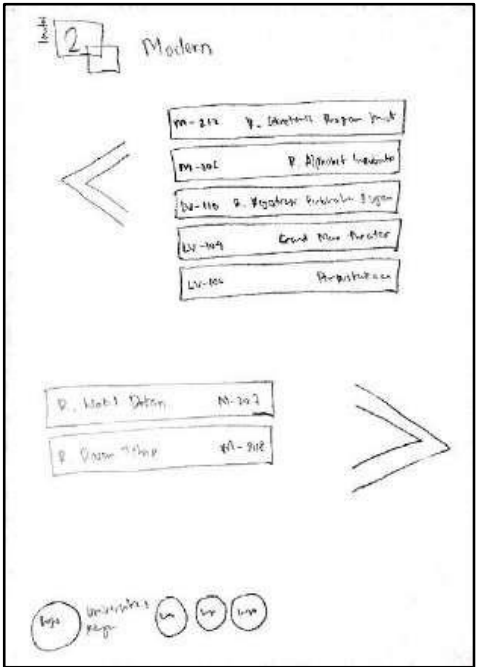

Gambar 6. Layout Kasar Koridor Kanan Lantai 2 Gedung Modern 
- Koridor Kiri Lantai 2 Gedung Modern

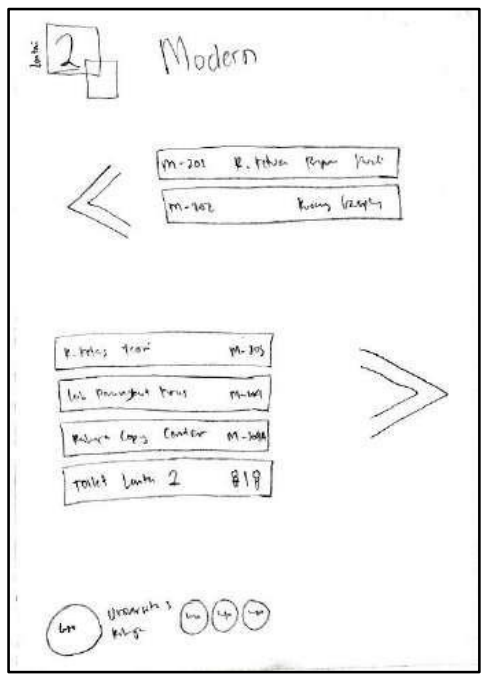

Gambar 7. Layout Kasar Koridor Kiri Lantai 2 Gedung Modern

- Koridor Kanan Lantai 3 Gedung Modern

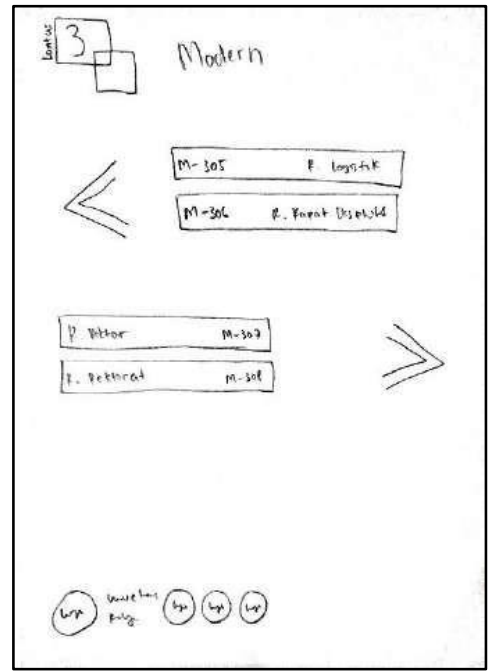

Gambar 8. Layout Kasar Koridor Kanan Lantai 3 Gedung Modern

\section{Layout Komprehensif}

Layout Komprehensif merupakan tahap selanjutnya setelah layout kasar. Proses desain pada tahap ini sudah memasuki tahap komputerisasi dan pewarnaan, tetapi dalam tahap ini belum selesai seluruhnya, karena masih harus mengalami proses revisi. Berikut merupakan layout komprehensif pada perancangan sign system: 

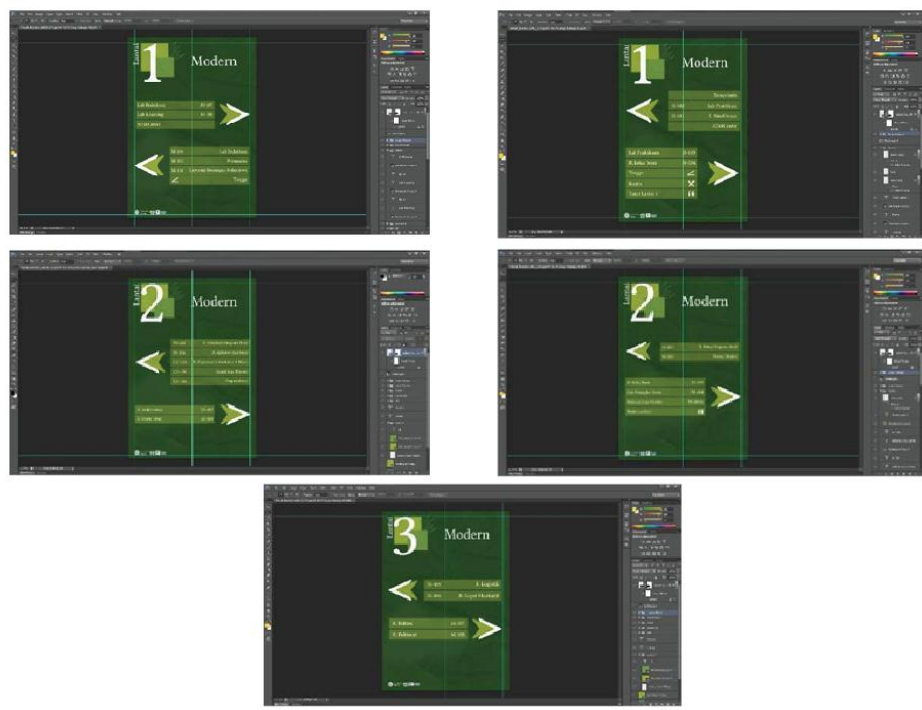

Gambar 9. Layout Komprehensif Seluruh Desain Sign System

Spesifikasi :

Ukuran Media : 42.0 x $59.4 \mathrm{~cm}$

Bahan: Art Carton 230 gram

\section{Final Artwork}

Final Artwork merupakan hasil akhir dari tata letak komprehensif yang ditingkatkan. Tahapan ini merupakan hasil akhir atau proses penyelesaian yang dapat dijadikan acuan dalam proses produksi.

- Koridor Kanan Lantai 1 Gedung Modern

Gambar : Terdapat arah panah yang menunjukan arah, gambar ilustrasi tangga, elemen desain, serta logo Universitas Raharja

Font : Libertinus Math

Warna: Hijau dan Putih

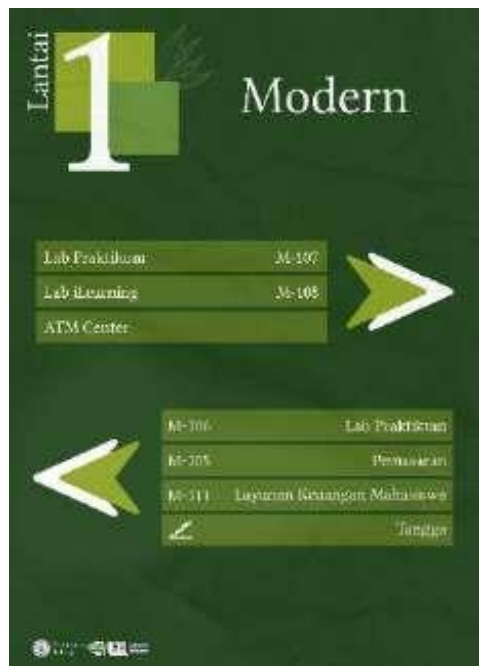

Gambar 10. Final Artwork Koridor Kanan Lantai 1 Gedung Modern 
- Koridor Kiri Lantai 1 Gedung Modern

Gambar: Terdapat arah panah yang menunjukan arah, gambar ilustrasi, elemen desain, serta logo Universitas Raharja

Font : Libertinus Math

Warna : Hijau dan Putih

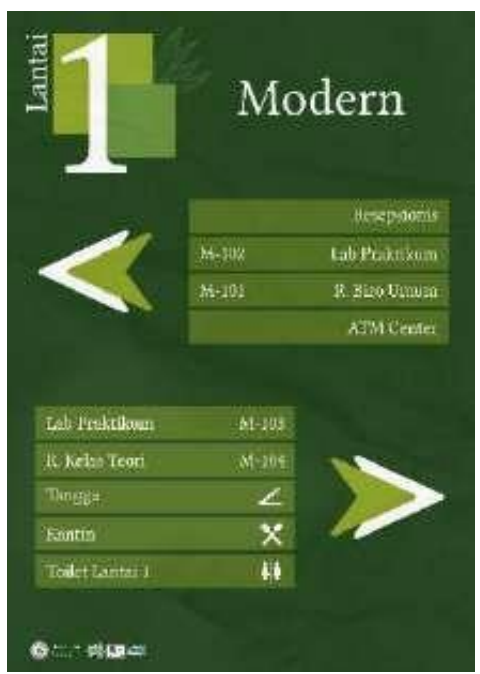

Gambar 11. Final Artwork Koridor Kiri Lantai 1 Gedung Modern

- Koridor Kanan Lantai 2 Gedung Modern

Gambar: Terdapat arah panah yang menunjukan arah, gambar ilustrasi, elemen desain, serta logo Universitas Raharja

Font : Libertinus Math

Warna: Hijau dan Putih

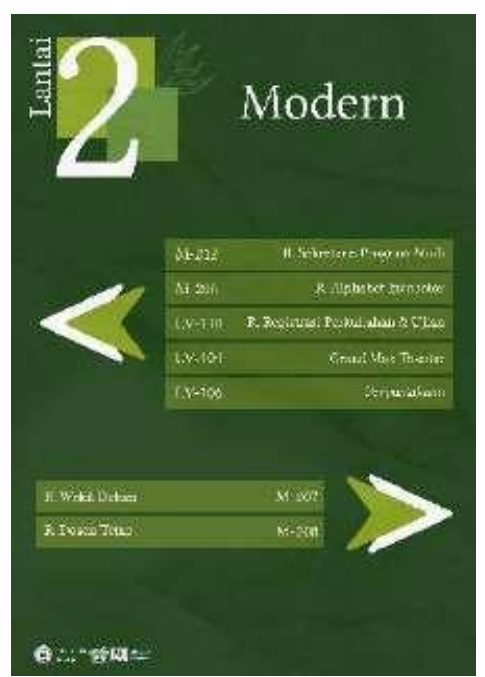

Gambar 12. Final Artwork Koridor Kanan Lantai 2 Gedung Modern 
- Koridor Kiri Lantai 2 Gedung Modern

Gambar: Terdapat arah panah yang menunjukan arah, gambar ilustrasi, elemen desain, serta logo Universitas Raharja

Font : Libertinus Math

Warna: Hijau dan Putih

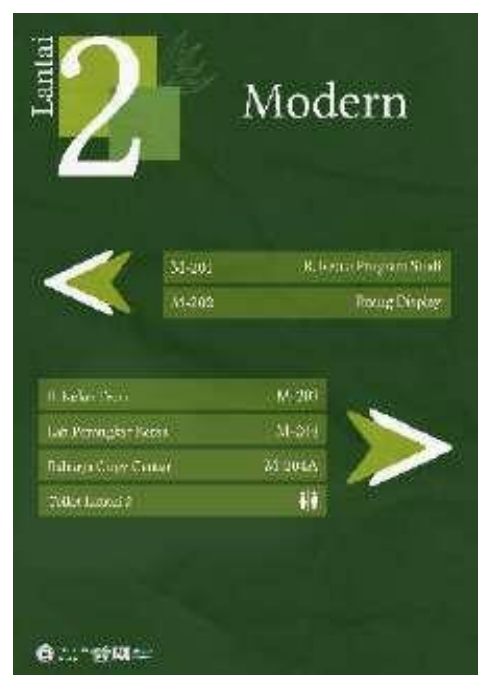

Gambar 13. Final Artwork Koridor Kiri Lantai 2 Gedung Modern

- Koridor Kanan Lantai 3 Gedung Modern

Gambar: Terdapat arah panah yang menunjukan arah, gambar ilustrasi, elemen desain, serta logo Universitas Raharja .

Font : Libertinus Math

Warna: Hijau dan Putih

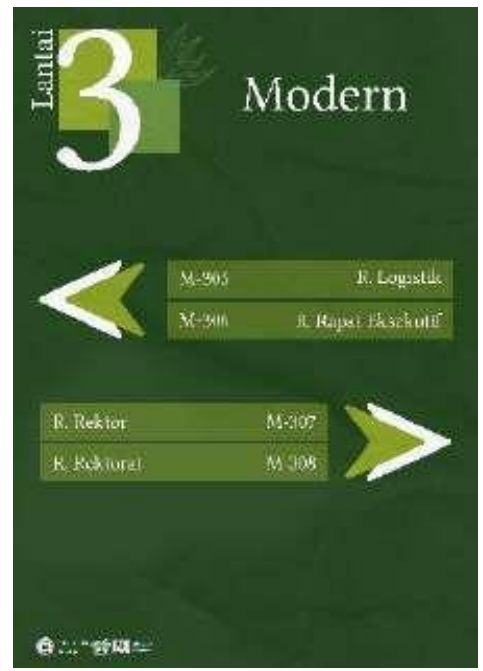

Gambar 14. Final Artwork Koridor Kanan Lantai 3 Gedung Modern

Melalui perancangan sign system ini didapati kesimpulan bahwa sangat diperlukan adanya pembuatan perancangan desain sign system ini guna menunjang sarana informasi pada Universitas Raharja, dan juga sebagai penyampaian informasi yang informatif dan komunikatif. 


\section{KESIMPULAN}

Berdasarkan penelitian dan analisa permasalahan kebutuhan informasi pada Universitas Raharja, diperoleh beberapa kesimpulan yaitu dalam perancangan sign system yang menarik guna menunjang sarana informasi pada Universitas Raharja dibuat dengan memperhatikan elemen desain grafis seperti warna, tipografi, tata letak, ilustrasi, dan menonjolkan elemen desain yang memenuhi kebutuhan informasi civitas Universitas Raharja. Kemudian penyampaian informasi yang informatif dan komunikatif pada Universitas Raharja melalui media sign system dengan bahasa indonesia dan arah panah yang mudah dimengerti dan dipahami oleh civitas Universitas Raharja. Lalu dengan placement sign system yang telah ditentukan dengan jelas dan diletakan pada tempat- tempat yang strategis, sehingga dapat menunjukan arah lokasi yang ingin dituju.

\section{SARAN}

Berdasarkan penelitian yang telah dilaksanakan, adapun beberapa saran yang dapat diberikan untuk Universitas Raharja yaitu agar kedepannya dapat mengembangkan media informasi dengan rancangan desain yang lebih interaktif dan kreatif, sehingga dapat menarik ketertarikan calon mahasiswa generasi baru, orang tua mahasiswa, dan tamu serta menunjang kebutuhan informasi pada Universitas Raharja. Kemudian disarankan untuk Universitas Raharja untuk selalu memberikan informasi terkini tentang tata letak ruangan maupun mengganti desain setiap 2 ataupun 3 tahun agar lebih menarik. Lalu disarankan untuk Universitas Raharja untuk lebih ditingkatkan kembali dalam penggunaan sign system ini agar bermanfaat dan terpenuhi kebutuhan informasi civitas Universitas Raharja.

\section{UCAPAN TERIMA KASIH}

Ucapan terima kasih disampaikan kepada semua pihak yang telah berperan dalam Perancangan Desain Komunikasi Visual Sign System Sebagai Sarana Penunjang Informasi Pada Universitas Raharja sehingga sistem ini dapat dituangkan dalam bentuk tulisan dan diinformasikan kepada tenaga kerja yang ada pada Universitas Raharja.

\section{DAFTAR PUSTAKA}

[1] Mujabfaqni, Agus. Tri Cahyo Kusumandyoko. 2016. Perancangan Sign System Taman Flora Surabaya. Surabaya: Universitas Negeri Surabaya. Jurnal Pendidikan Seni Rupa, Vol.04, No.03: 382.

[2] Andrijanto, MS. 2018. Perancangan Alternatif Sign System Sebagai Informasi Lokasi Penjualan Di Pasar Legi Kota Gede. Jakarta Selatan : Universitas Indraprasta PGRI. Jurnal Design. ISSN: 2339-0115. Vol.5, No.03: 226.

[3] Andrijanto, MS. 2018. Perancangan Alternatif Sign System Sebagai Informasi Lokasi Penjualan Di Pasar Legi Kota Gede. Jakarta Selatan: Universitas Indraprasta PGRI. Jurnal Design. ISSN: 2339-0115. Vol.5, No.03: 226.

[4] Ramadia, Ramadia. Zubaidah dan San Ahdi. 2017. Perancangan Komunikasi Visual Sign System Semen Padang Hospital. Padang: Universitas Negeri Padang. DEKAVE (Jurnal Desain Komunikasi Visual). ISSN: 2302-3228. Vol.5, No.2: 7-8.

[5] Adzhar, Ramzy. Wirania Swasty. 2019. Perancangan Sign System Yang Terintegrasi Website Sebagai Media Informasi. Bali : STMIK STIKOM Indonesia. Jurnal Bahasa Rupa. ISSN: 2581- 0502. Vol. 3. No.1:36. 
[6] Putra, Nanda Kurnia. M. Nasrul Kamal dan Juprian. 2018. Redesign Sign System Puskesmas Lubuk Buaya Koto Tanggah Kota Padang. Padang: Universitas Negeri Padang. DEKAVE (Jurnal Desain Komunikasi Visual). ISSN: 2302-3228. Vol.8, No.2: 2.

[7] Mujabfaqni, Agus. Tri Cahyo Kusumandyoko. 2016. Perancangan Sign System Taman Flora Surabaya. Surabaya: Universitas Negeri Surabaya. Jurnal Pendidikan Seni Rupa, Vol.04, No.03: 382.

[8] Sunarya, Abas. Sugeng Santoso dan Subhan Ahmad Saputra. 2020. Rancang Bangun Sistem Informasi Pengukuran Kepuasan Siswa Sebagai Penunjang Keputusan. Tangerang: Universitas Raharja, ICIT (Innovative Creative and Information Technology) Journal. ISSN: 2654-8704 Vol. 6 No.1: 13.

[9] Rizqullah, Mohamad Farid dan Wirania Swasty. 2019. Perancangan Media Informasi Kota Tua Jakarta Utara Melalui Sign System Yang Terintegrasi Website. Semarang: Universitas Dian Nuswantoro Semarang. Andharupa: Jurnal Desain Komunikasi Visual \& Multimedia. ISSN: 2477-3913. Vol. 5, No.2: 210-225.

[10] Hendrizal, Muhammad Habib. 2019. Perancangan Sign System Pada Master Plan Kampus Universitas Negeri Padang. Padang: Universitas Negeri Padang. DEKAVE (Jurnal Desain Komunikasi Visual). ISSN: 2302-3228. Vol.8, No.3: 1-16.

[11] Tsao, Yung-Chin. Shang-li Chu, Ching-Huei Lai dan Shih-Yin Huang. 2020. Universal Design Evaluation Applied On Station Sign System Innovation Design. International Journal of Organizational Innovation. 2020-1078 IJOI. Vol. 13, No.1: 360382.

[12] Iftikhar, H. Salman Asghar and Yan Luximon. 2020. The efficacy of campus wayfinding signage: a comparative study from Hong Kong and Pakistan. ISSN: 0263-2772. Vol. 38, No. 11: 871-892. 